\title{
First-year dental students' motivation and attitudes for choosing the dental profession
}

\begin{abstract}
Nadya Avramova ${ }^{1}$, Krassimira Yaneva $^{2}$, Boyko Bonev ${ }^{3}$
${ }^{1}$ Medical University - Sofia, Bulgaria Faculty of Dental Medicine, Department of Dental Public Health

${ }^{2}$ Medical University - Sofia, Bulgaria

Faculty of Dental Medicine, Department of Dental Public Health

${ }^{3}$ Medical University - Sofia, Bulgaria

Faculty of Dental Medicine, Department

of Dental Public Health

Corresponding author:

Nadya Avramova

Faculty of Dental Medicine

1 Georgi Sofiiski Str.

1431 Sofia, Bulgaria

avramova_nadia@abv.bg

Tel.: + 359898609286

Fax.: + 35929521506

Received: 28 May 2014

Accepted: 23 September 2014

Copyright $\odot 2014$ by

Objective. To determine first-year dental students' current motivation and attitudes for choosing the dental profession at the Faculty of Dental Medicine, Medical University - Sofia, Bulgaria. Material and methods. An anonymous questionnaire, consisting of 12 questions about students' socio-demographic profile and their motivation for choosing dentistry, was administered to 119 first-year dental students at the Faculty of Dental Medicine of the Medical University of Sofia. The study was conducted at the beginning of the 2012-2013 academic year. The data was processed and analyzed with the following software: Microsoft Windows Server 2008 R2; Microsoft SQL Server 2008; Internet Information Server 7.5.; Microsoft SharePoint Server 2010. Results. The majority of the students (73\%) were self-motivated for choosing dentistry as a career; $61 \%$ of them did not have relatives in the medical profession; $43 \%$ chose dental medicine because it is a prestigious, humane and noble profession; $50 \%$ - for financial security; $59 \%$ - because of the independence that it provides. There were no significant differences in the motivation between males and females. Conclusion. Independence, financial security and 'prestige' were the predominant motivating factors in this group of first-year dental students. Determining the reasons for choosing dentistry has important implications for the selection and training of students as well as for their future job satisfaction.
\end{abstract}

Academy of Sciences and Arts

of Bosnia and Herzegovina.

E-mail for permission to publish:

amabih@anubih.ba
Key words: Dental students, Dentistry, Motivation, Job satisfaction.

\section{Introduction}

The reasons for choosing a particular profession are very complex, and the choice of dentistry is no exception (1). Many factors influence the choice of a profession: an individual's strengths and weaknesses, personal interests and desires, willingness and financial ability (or inability) to endure a long period of training related to a specific profession, the social prestige of the profession; the actual type of work that is inherent in the profession, working conditions, financial compensation associated with the profession and the availability and attractiveness of alternative occupations $(1,2)$.

A critical look (over time and across different countries) of the research literature on the motivation of people, who chose dentistry as a career, shows a wide variety of motivating factors (1, 3-7). Most studies were 
based on surveys and used various methodologies. The results of these studies are not easily compared. There is common agreement, both on the large number of motivating factors and the fact that dominant motivational factors can vary significantly, over time and between countries. Moreover, from a sociological point of view, the emerging workforce today has very different expectations from those of previous generations (8).

Scarbecz and Ross (1) examined the motives of first-year students (University of Tennessee, USA) for selecting the dental profession, demographic data and future professional plans. Their study identified four key factors or groups of reasons for choosing the dental career:

- A financial motive - focuses on the financial and professional stability;

- A people -oriented or caring motive refers to interpersonal relationships and the ability to take care of and help other people;

- A flexibility motive - dentists have greater freedom and flexibility in planning their work time compared with other professions connected or not connected to protecting public health;

- A business-oriented motive - focuses on the extent to which students believe that independence and self-management of their activities are important reasons for choosing the dental profession.

In this study the authors present and analyze data on the socio-demographic profile and reasons for the professional choice of first-year dental students in the Faculty of Dental Medicine, Medical University - Sofia for the 2012-2013 school year, as well as their premises regarding the nature of their future profession.

The aim of this study was to determine first-year dental students' motivation and preliminary attitude for choosing the dental profession at the Faculty of Dental Medicine, Medical University - Sofia, Bulgaria.

\section{Materials and methods}

\section{Respondents}

This study was approved by The Ethical Committee of the Medical University of Sofia (number 6506/18.12.2013). The research was carried out in compliance with the Helsinki Declaration. The study was conducted among newly enrolled dental students at the beginning of the 2012-2013 academic year at the Faculty of Dental Medicine of the Medical University of Sofia, Bulgaria. The total number of first-year dental students enrolled at the beginning of each academic year is 120 persons (60 males and 60 females).

\section{Data collection}

After sufficiently clear and detailed information about the purpose of the study had been given to the students, they were given the questionnaire (Appendix) and were asked to respond to this survey anonymously. The completion of the questionnaire by each student was taken as a form of individual consent to participate in the study.

\section{Material}

The self-administrated questionnaire (Appendix) contained 12 questions which were related to: Students' socio-demographic characteristics; Students' motivation for choosing the dental profession; Students' opinion and preliminary attitudes towards the dental profession. Some of the questions required the students to respond merely with a "yes" or "no", such as the question, "Do you have any close relative (mother, father, siblings, etc) in the medical profession?". Other questions offered one or several possible answers and the respondents had to choose one or several, for example, the questions related to the basic motives for choosing dentistry as a career. This type of 
questions also had a blank space that was left for writing other answers if the students had any. The third group were open questions with an option for writing different answers. For example: "How many times did you apply for dentistry?"“.

\section{Data Processing}

The information was processed and analyzed using the following software: Microsoft Windows Server 2008 R2; Microsoft SQL Server 2008; Internet Information Server 7.5; Microsoft SharePoint Server 2010.

\section{Results}

A total of 119 students (99.2\%) responded to the survey. Of these, $62(52.1 \%)$ were women and $57(47.9 \%)$ - men, aged 18 to 32 years (Figure 1). As shown in Figure 1, the number of students aged 19 years prevailed - $69(57.9 \%)$. There were 31 students aged 18 (26.1\%) and 10 aged 20 (8.4\%). There was a small number of students aged $21,22,23,25,28$ and 32 years - respectively 2 (1.7\%), 2 (1.7\%), 2 (1.7\%), 1 $(0.8 \%), 1(0.8 \%)$ and $1(0.8 \%)$.
The majority of the students graduated from high school: 58 (48.7\%) students graduated from language high schools, 34 (28.6\%) from mathematics high schools and $21(17.7 \%)$ - from ordinary high schools. Two students (1.7\%) graduated from technical schools, 2 (1.7\%) from other universities, $1(0.8 \%)$ from dental technician college and $1(0.8 \%)$ from nursing college (Figure 2$)$.

More than half the newly enrolled students $-72(60.5 \%)$ reported that they did not have relatives - a mother, father, brother or sister - in the medical profession. For 87 (73.1\%) of the students the choice of dentistry was a result of their own decision. A much smaller number of students were influenced by their parents $-28(23.5 \%)$, by a dentist $-16(13.5 \%)$, friends $-3(2.5 \%)$ or teachers $-1(0.8 \%)$. For some respondents the decision was a result of several factors (Figure 3).

According to the results, $3 / 4$ of the students - $89(74.8 \%)$ - decided to apply for dentistry in high school, 22 (18.5\%) - before high school, and only 8 (6.7\%) - after completing their secondary education.

Students were asked two questions related to their eagerness to study dentistry. To

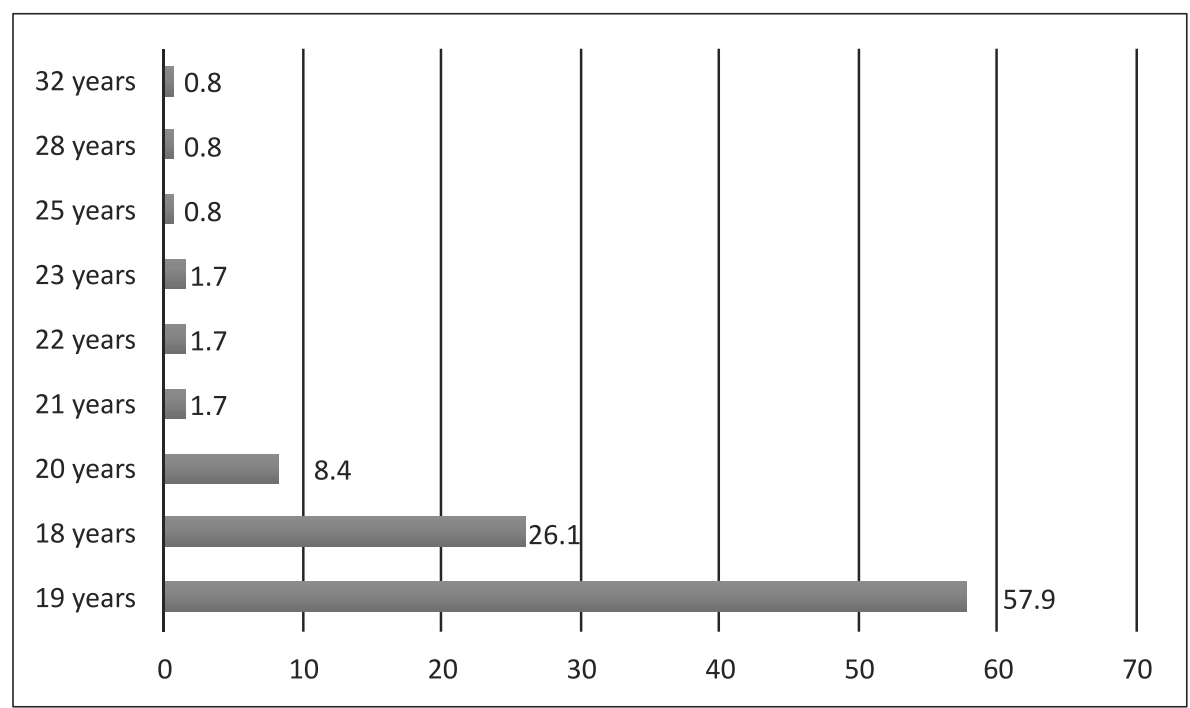

Figure 1 Distribution (\%) of students by age groups. 


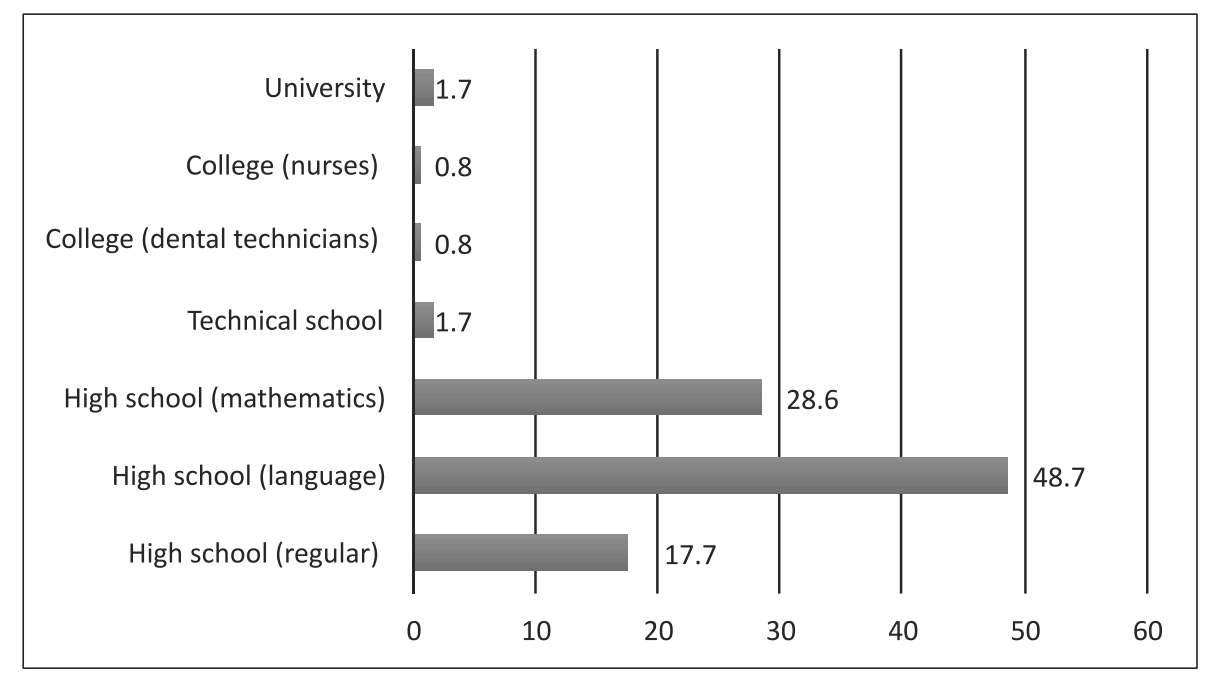

Figure 2 Distribution (\%) of the students according to the type of school they graduated from.

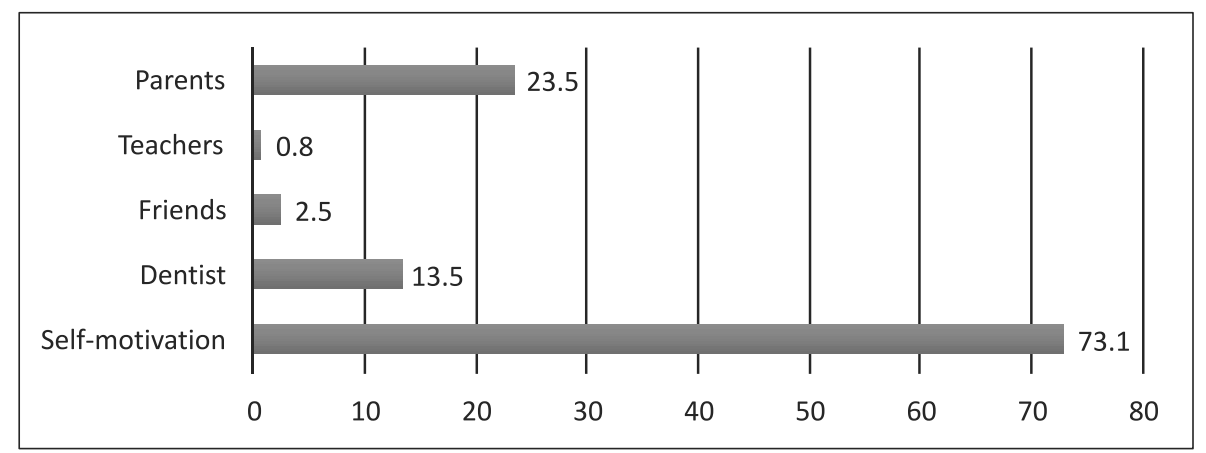

Figure 3 Distribution (\%) of students according to the source of their motivation to study dentistry.

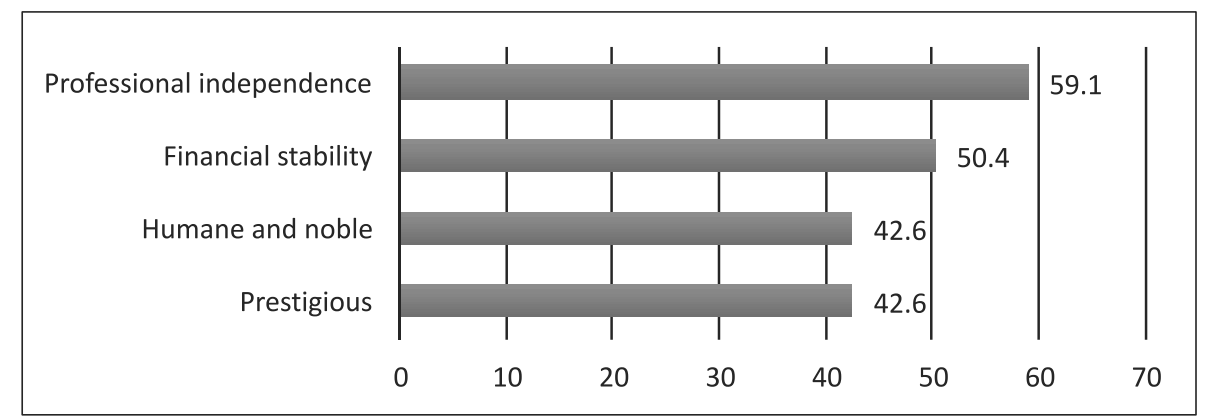

Figure 4 Distribution (\%) of students according to their motives for choosing dentistry.

the first question: "How many times did you apply for dentistry?" 101 (84.9\%) responded that it was their first attempt, $16(13.5 \%)$ had applied for a second time and $2(1.7 \%)-$ for a third time. A total of 116 respondents answered the second question: "What was your first choice?" The results showed that $110(94.8 \%)$ of the students indicated dental medicine as their first choice and only 6 (5.2\%) chose medicine. 


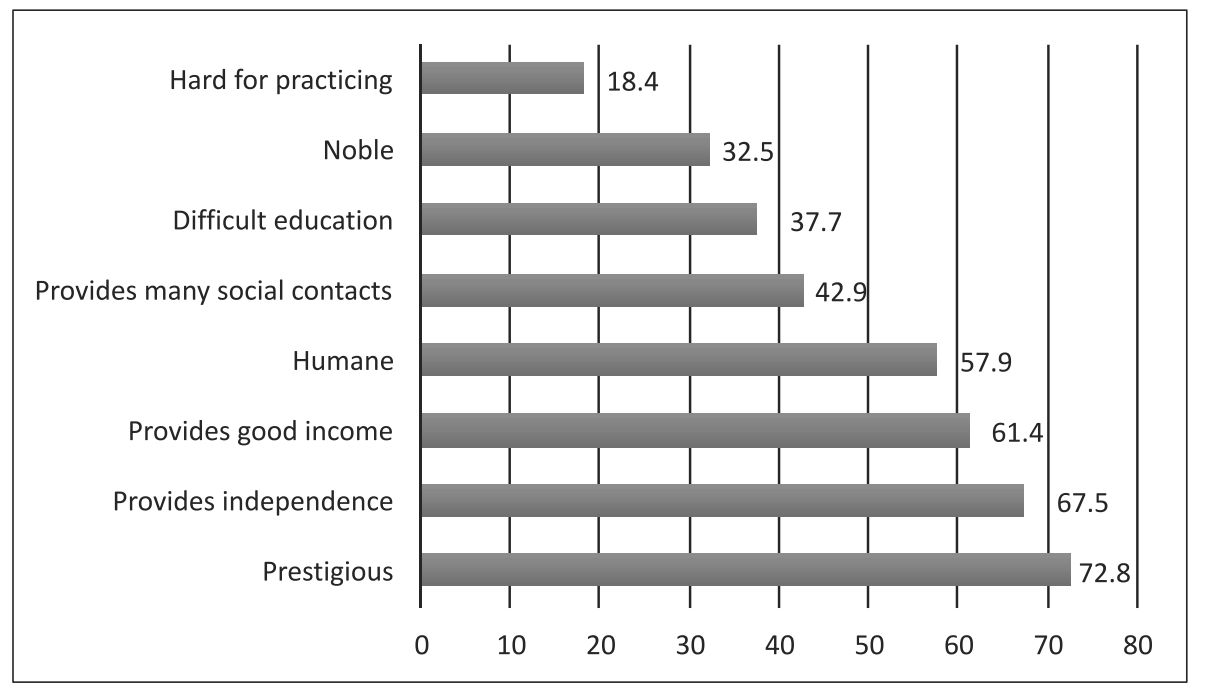

Figure 5 Distribution (\%) of students according to their attitudes towards the dental profession.

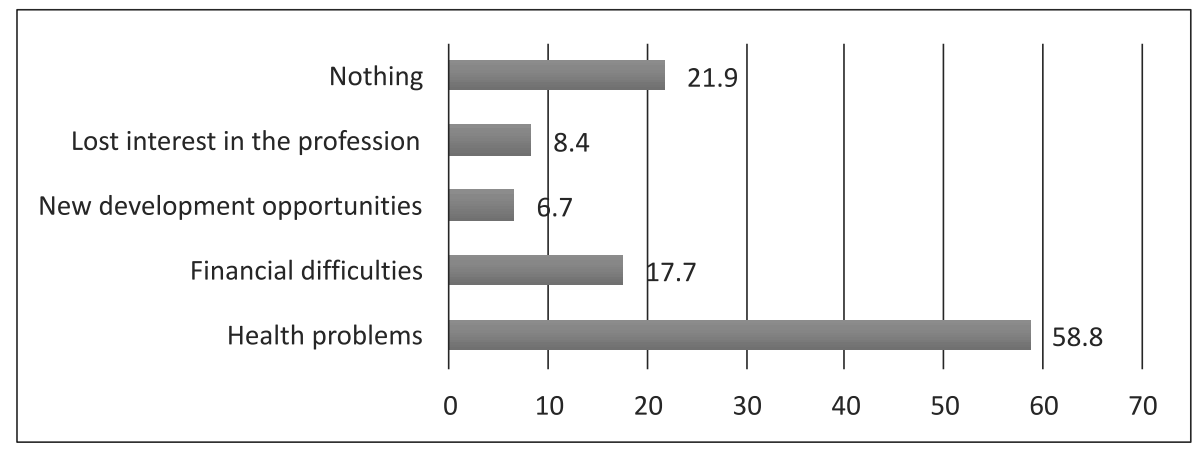

Figure 6 Distribution (\%) of students according to the reasons for terminating their education.

No one chose pharmacy as an option. The students' preliminary opinion regarding the dental profession was expressed in the answers to questions № 9 and 10.115 students explained their choice to become dentists by giving more than one answer: 49 (42.6\%) of them chose dentistry as a prestigious profession; also 49 (42.6\%) because it is humane and noble; 58 (50.4\%) for financial stability, and $68(59.1 \%)$ because it provides autonomy to the practitioner (Figure 4).

Determining the students' attitudes and perceptions about the dentist's profession was also important for the purpose of this study. 114 respondents answered the question: "What do you know about the chosen profession?". 83 (72.8\%) of them believed it to be a prestigious profession, $77(67.5 \%)$ that it provides autonomy, $70(61.4 \%)$ that it provides a good income, $66(57.9 \%)$ that it is humane, $49(42.9 \%)$ that it is a profession that provides a large number of social contacts, $43(37.7 \%)$ that it is difficult to study, $37(32.5 \%)$ considered that the dental profession is noble, and only $21(18.4 \%)$ thought that it is hard to practice (Figure 5).

The students again gave more than one response to this question. The last two questions were related to the students' opinion about the potential changes in their future education. The answer to the question "What could make you terminate your education?" is presented in Figure 6. 
For $70(58.8 \%)$ of the respondents, health problems were a serious reason for interrupting their education, 21 (17.7\%) considered that financial difficulties would interrupt their education, 8 (6.7\%) would leave the university if new opportunities for development arose and $10(8.4 \%)$ if they lost interest in the profession. Nothing could make $26(21.9 \%)$ of the students give up their chosen education. Only $2(1.7 \%)$ of the respondents would try to transfer to another university. The remaining 113 (94.9\%) responded negatively to the question: "Will you try to transfer to another university?" and 4 students (3.4\%) did not answer it.

\section{Discussion}

The discussion of issues related to students' motivation and attitudes towards their future profession cannot be considered separately from the specific social, economic and political environment. Moreover, it should be constantly adapted to changes in the profession, health policy and increased demands of society (9). The fact is that the reasons for choosing the dental profession have the potential to change over time (3). However, personal views and concepts about the profession are major influencing factors for choosing dentistry as a career (10). Therefore it is essential to clarify whether the choice of a profession is a matter of an individual's decision or whether it was influenced by other people.

Students' motivation and their preliminary attitude to the dental profession are associated with a dentist's future job satisfaction. Considering the Two-Factor Theory of job satisfaction (11), there are intrinsicmotivation and extrinsic-hygiene factors. The presence of intrinsic motivation facilitates higher satisfaction and performance, whereas the absence of extrinsic factors helps mitigate against dissatisfaction (12). Both components of the theory, intrinsic and extrinsic, are essential for dentists, but the presence of intrinsic motivating factors has the most positive impact on job satisfaction (12).

The present findings indicated that the majority of the students (73\%) were selfmotivated to study dentistry. Yolov (13) conducted a survey of professional satisfaction among 327 dentists, and found that the majority of them (83.5\%) made the decision to apply for dentistry on their own. The remainder, $16.5 \%$, were influenced by relatives, or because their exam score was not high enough for their first choice (medicine or pharmacy). The author reported that the proportion of dissatisfied dentists was mainly formed by those who were influenced by relatives or those who were not practicing their preferred profession (13).

There were similar results from a survey conducted in Australia by Marino et al. during the 2009-2010 academic year (14). According to this survey, $85.3 \%$ of the students were mostly self-motivated to pursue a dental career (14). According to the results of the current study, the influence of the students' parents was significantly less (24\%) than their self-motivation. Furthermore, over half of the students did not have relatives in the medical profession (61\%). Conversely, the results of a study conducted by Tanalp et al. (15), concerning the future expectations of the students enrolled to study at the first private dental school in Istanbul (Turkey), presented the key role of the students' relatives (mother, father, brother, sister, etc.). According to this study, students' fathers and mothers had a similar impact on forming their choice (respectively $45.9 \%$ and $46.6 \%)(15)$.

In the current survey it was found that the influence of other people rather than relatives was less. $13 \%$ of the future dentists were influenced to choose this profession by a dentist, $3 \%$ by friends and only $1 \%$ by a teacher. A study conducted in Nevada, USA 
by Hawley et al. (16) involving 152 first-year students and aiming to clarify their attitudes to the dental profession, showed that a large proportion of the respondents (52.6\%) indicated their family dentist as the person who had the greatest influence on their decision.

The process of decision making about the future career requires the availability of sufficient time for understanding the priorities and future consequences related to the profession. The majority (75\%) of the Bulgarian students surveyed made this decision while studying in high school. The data obtained did not differ significantly from those of other studies on similar topics $(7,14,16)$.

The philosophy associated with education, the requirements for university admission and the procedures related to students' selection, undoubtedly affect their sociodemographic profile (7). Therefore the majority of Bulgarian freshmen students were aged 18,19 or 20 years, which means that they applied for dentistry immediately after completing their secondary education. They were also representatives of the leading schools in Bulgaria (Language and Mathematics High Schools). Moreover, almost all the students (95\%) indicated dentistry as their first choice and $85 \%$ of them had applied for this specialty for the first time. These facts prove the students' eagerness to explore the aspects of the dental profession: to work with and for people, to be independent and financially secure, and to be satisfied with their profession $(5,7)$.

The features of the dental profession, as mentioned above, are present in the students' perception and attitudes about the nature of their future profession. The majority of them $(73 \%)$ believe that it is a prestigious occupation; $68 \%$ consider that it provides independence to the practitioner and for $61 \%$ of the students the dental profession is related to a good income. However, the awareness about the nature of the future profession could (and should) not be the same as the reasons for choosing it. It was detected that, in contrast, the students' motives regarding their choice of career showed that only $43 \%$ chose dentistry because it is a prestigious, humane and noble profession; the financial stability associated with the profession, appeared in second place (50\%) and the main and leading motive for choosing the dental profession indicated by the students, was the independence they would have as practicing dentists (59\%).

Undoubtedly concepts such as "helping others", financial stability, independence and many others, have different meanings to different people (4). The authors found only one study in which the financial motive was the first for choosing dentistry. Aguiar et al. (17) examined 1,024 students in Pernambuco (Brazil), to establish the factors leading to choosing dentistry as a profession. The results of this study showed that $73.5 \%$ of the students chose the dental profession mainly due to economic reasons (17).

There were more sources where the leading reasons for choosing dentistry were indicated, such as: the respect and prestige associated with the dental profession; the fact that "I help others"; job satisfaction, etc. According to students in Johannesburg (South Africa), Sydney (Australia) and Amman (Jordan) the independence and financial stability that the dental profession provides were not so important reasons for choosing dentistry as a career $(3,5,9,18)$.

\section{Conclusions}

From the conducted study it can be concluded that:

1. The majority of Bulgarian students were self-motivated for choosing dentistry as a career;

2. According to the Bulgarian first-year dental students, the leading motives for choosing the dental profession are as follows: a) The profession "dentistry" provides 
independence for the practitioner; b) It provides financial stability; c) It is a prestigious, humane and noble occupation;

3. Students' perception about their future profession is associated with the prestige, independence and financial stability characterizing the dental profession.

Determining the preliminary attitude to the profession, as well as the leading reasons for pursuing it are closely linked to the practitioners' future job satisfaction. Not so precisely clarifying the nature and characteristics of the future profession is a major prerequisite for further disappointment with it. Therefore, students' motivation and attitudes for choosing the dental profession should be considered in the selecting and training of students, if job satisfaction in dental practice is to be achieved.

Acknowledgements: The authors would like to thank the first-year students at the Medical University of Sofia, Faculty of Dental Medicine, for taking part in this survey.

Authors' contributions: Conception and design: NA and KY; Acquisition, analysis and interpretation of data: NA and BB; Drafting the article: NA; Revising it critically for important intellectual content: NA, BB, KY.

Conflict of interest: The authors declare that they have no conflict of interest.

\section{References}

1. Scarbecz M, Ross JA. Gender differences in firstyear dental students' motivation to attend dental school. J Dent Educ. 2002;66(8):952-61.

2. Gati I, Osipow SH, Givon M. Gender differences in career decision making: the content and structure of preferences. J Couns Psychol. 1995; 42(2):204-16.

3. Brand A, Chikte U. Choosing dentistry as a career - Part I: A comparison of student motives. J Dent Assoc South Africa. 1992;47(11):469-73.

4. Brand A, Chikte U. Choosing dentistry as a career - Part II - The meaning of motives. J Dent Assoc South Africa. 1992;47(12):509-12.

5. Brand AA, Chikte UM, Thomas CJ. Choosing dentistry as a career - A profile of entering students (1992) to the University of Sydney, Australia. Aust Dent J. 1996;41(3):198-205.
6. Gallagher JE, Patel R, Donaldson N, Wilson NH The emerging dental workforce: why dentistry? A quantitative study of final year dental students' views on their professional career. BMC Oral Health. 2007;7:7. Available from: http://www.biomedcentral.com/1472-6831/7/7.

7. Thomson W, Marshall R, Gotjamanos T, Evans W, Marino RJMM, Winning T. Sociodemographic backgrounds and career decisions of Australian and New Zealand dental students. J Dent Educ. 2006;70(2):169-78.

8. Gallagher J, Clarke W, Eaton KA, Wilson NH. Dentistry - a professional contained career in healthcare. A qualitative study of vocational dental practitioners' professional expectations. BMC Oral Health. 2007;7:16. Available from: http://www. ncbi.nlm.nih.gov/pmc/articles/PMC2200640/.

9. Brand AA, Chikte UM. Student attitudes to dentistry in South African dental schools. J Dent Assoc South Africa. 1997;52(12):713-20.

10. Freire MCM, Jordao LMR, Ferreira NP, Nunes MF, Queiroz MG, Leles CR. Motivation towards career choice of Brazilian freshman students in a fifteenyear period. J Dent Educ. 2011;75(1):115-21.

11. Herzberg F, Mausner B, Snyderman BB. The Motivation to Work. 2nd ed. New York: John Wiley \& Sons; 1959.

12. Goetz K, Campbell SM, Broge B, Dorfer CE, Brodowski M, Szecsenyi J. The impact of intrinsic and extrinsic factors on the job satisfaction of dentists. Community Dent Oral Epidemiol. 2012;40(5):474-80.

13. Yolov ZV. Satisfaction of Stomatologists in Their Own Profession [In Bulgarian]. Stomatology. 1986;2:57-60.

14. Marino R, Au-Yeung W, Habibi E, Morgan M. Sociodemographic profile and career decisions of Australian oral health profession students. J Dent Educ. 2012;76(9):1241-9.

15. Tanalp J, IIguy D, Dikbas I, Oktay I. Demographic profile and future expectations of students enrolled in a Turkish private dental school. J Dent Educ. 2012;76(6):800-9.

16. Hawley NJ, Ditmyer MM, Sandoval VA. Predental students' attitudes toward and perceptions of the dental profession. J Dent Educ. 2008;72(12):1458-64.

17. Aguiar CM, Pessoa MA, Camara AC, Perrier RA, Figueiredo JA. Factors involved in the choice of dentistry as an occupation by Pernambuco dental students in Brazil. J Dent Educ. 2009;73(12):1401-7.

18. Al-Bitar ZB, Sonbol HN, Al-Omari IK. Reasons for choosing dentistry as a career by Arab dental students. Eur J Dent Educ. 2008;12(4):247-51. 


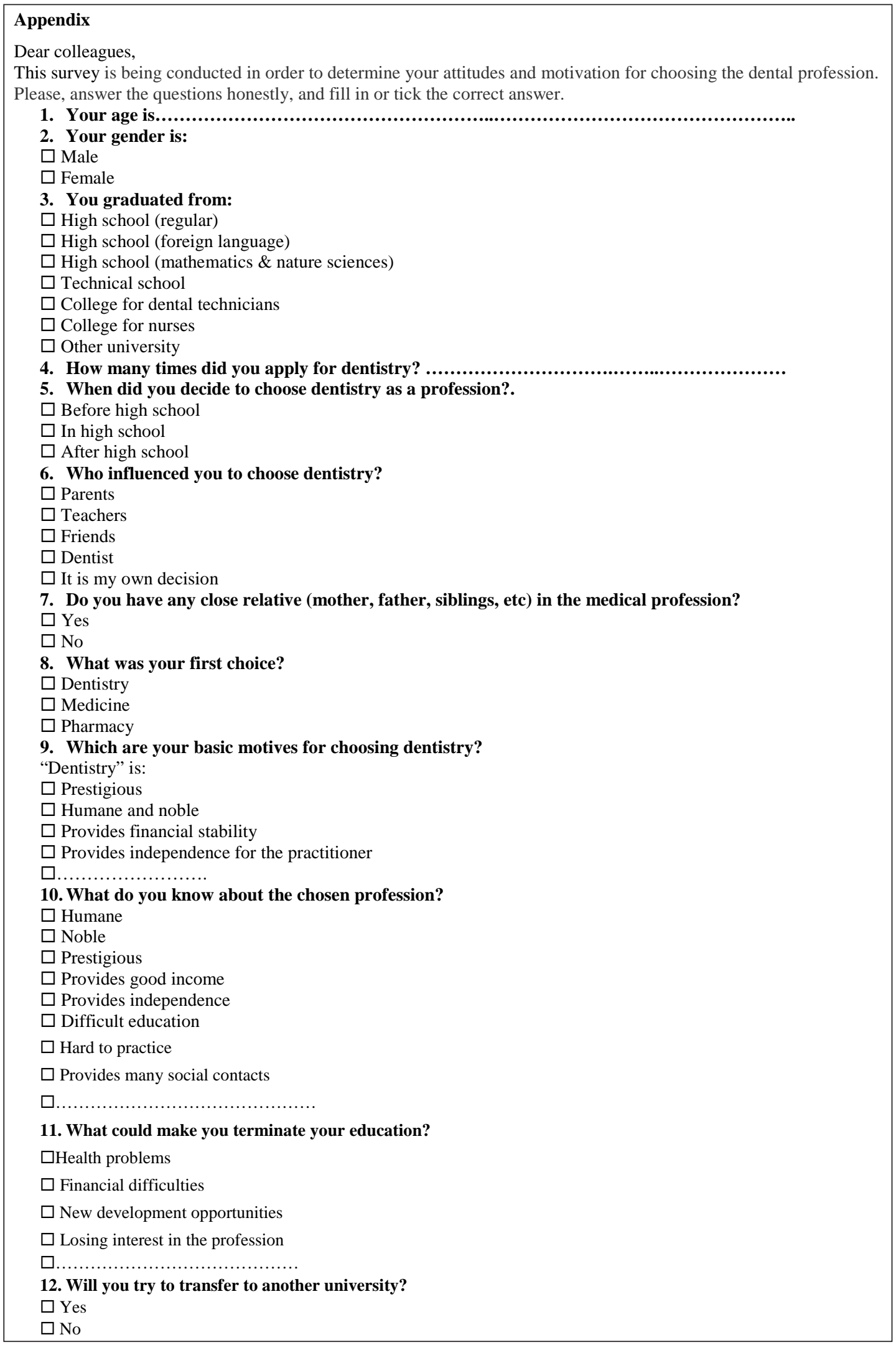

